\title{
Brain [18F]FDG PET-CT imaging in posterior cortical atrophy
}

\author{
Imagem cerebral por [18F]FDG-PET-CT na atrofia cortical posterior
}

Marcelo Houat DE BRITO', Poliana Fonseca ZAMPIERI', Artur Martins COUTINHO², Sonia Maria Dozzi BRUCKI ${ }^{1}$

A 68-year-old woman presented with a four-year history of progressive difficulty performing daily activities like dressing, and sometimes colliding with objects when walking. An ophthalmology consultant excluded primary visual changes. Evaluation revealed apperceptive visual agnosia, simultanagnosia, optic ataxia, oculomotor, dressing and constructive apraxia. Other cognitive domains were relatively spared. Brain [18F]FDG-PET-CT showed bilateral temporoparietal hypometabolism with occipital cortex extension (Figure), compatible with the hypothesis of posterior cortical atrophy ${ }^{1,2}$, a neurodegenerative syndrome with an early and progressive decline in visuospatial and visuoperceptual skills, attributable to Alzheimer's disease pathology in most patients ${ }^{3}$, that could be assessed by cerebrospinal fluid biomarkers, which were not available in this case.
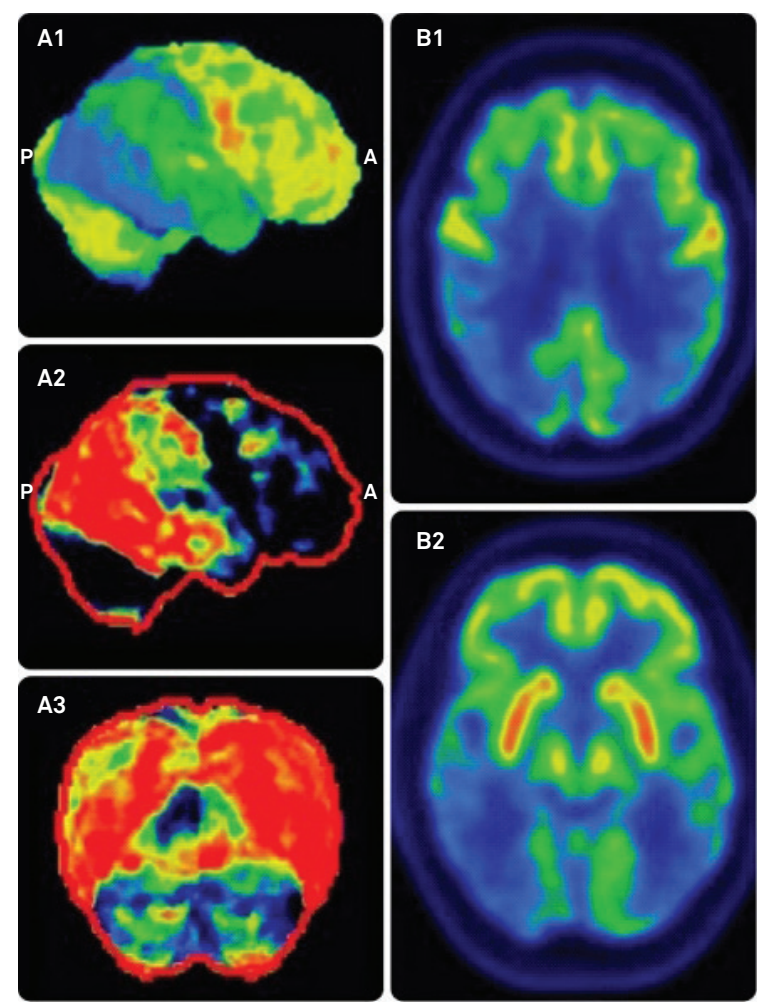

Figure. Brain [18F]FDG-PET images showing bilateral temporoparietal hypometabolism with extension to the occipital cortex, including its superior parts and transition with the temporal and parietal lobes. Left column - 3D-SSP reconstructions of the brain metabolic map in the right lateral projection (A1) and projection of the Z-map comparison with a group of healthy individuals in the right lateral (A2) and posterior views (A3). Right column - [18F]FDG-PET transaxial views.

\footnotetext{
'Universidade de São Paulo, Faculdade de Medicina, Hospital das Clínicas, Departamento de Neurologia, São Paulo SP, Brasil; ${ }^{2}$ Universidade de São Paulo, Faculdade de Medicina, Hospital das Clínicas, Centro de Medicina Nuclear, Departamento de Radiologia, São Paulo SP, Brasil. Marcelo Houat de Brito iD https://orcid.org/0000-0001-7521-1388; Poliana Fonseca Zampieri iD https://orcid.org/0000-0002-5364-6337; Artur Martins Coutinho (iD) https://orcid.org/0000-0002-5555-4583; Sonia Maria Dozzi Brucki (iD) https://orcid.org/0000-0002-8303-6732

Correspondence: Marcelo Houat de Brito; Departamento de Neurologia HC-FMUSP; Av Enéas de Carvalho Aguiar, 255; 05403-000 São Paulo SP, Brasil; E-mail: marcelohbrito@gmail.com

Conflict of interest: There is no conflict of interest to declare.

Received 12 January 2019; Received in final form 01 April 2019; Accepted 08 April 2019.
} 


\section{References}

1. Whitwell JL, Graff-Radford J, Singh TD, Drubach DA, Senjem ML, Spychalla AJ, et al. 18F-FDG PET in posterior cortical atrophy and dementia with Lewy bodies. J Nucl Med. 2017 Apr;58(4):632-8. https://doi.org/10.2967/jnumed.116.179903

2. Singh TD, Josephs KA, Machulda MM, Drubach DA, Apostolova LG, Lowe VJ, et al. Clinical, FDG and amyloid PET imaging in posterior cortical atrophy. J Neurol. 2015 Jun;262(6):1483-92. https://doi.org/10.1007/s00415-015-7732-5

3. Crutch SJ, Lehmann M, Schott JM, Rabinovici GD,

Rossor MN, Fox NC. Posterior cortical atrophy. Lancet Neurol. 2012 Feb;11(2):170-8.

https://doi.org/10.1016/S1474-4422(11)70289-7 